\section{SPR⿴囗十 Global Journal of Foreign Language Teaching}

Volume 07 , Issue 1, (2017) 46-51

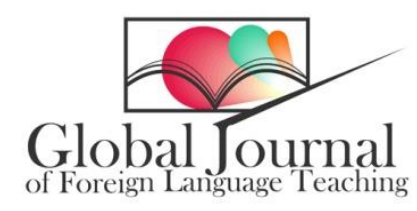

www.gjflt.eu

\title{
Bio-Cognitive aspects of simple and progressive verb forms usage
}

Andrey Druzhinin*, Department of Foreign Languages, Moscow State Institute of International Relations Ministry of Foreign Affairs, 119454, Russia

Svetlana Pesina, Department of English philology and cultural linguistics, Saint Petersburg State University, 199034, Sankt-Peterburg, Russia.

Ali Rahimi, School of Humanities and Tourism Management, Bangkok University, 10110, Thailand.

\section{Suggested Citation:}

Druzhinin, A., Pesina, S. \& Rahimi, A. (2017). Bio-Cognitive aspects of simple and progressive verb forms usage. Global Journal of Foreign Language Teaching. 7(1), 46-51.

Received September 16, 2016; revised November 23, 2016; accepted February 25, 2017

Selection and peer review under responsibility of Assoc. Prof Dr. Ali Rahimi, Bangkok University, Thailand. C2017 SciencePark Research, Organization \& Counseling. All rights reserved.

\begin{abstract}
The article offers a cognitive subject-oriented perspective on language and its acquisition with a focus on grammar. By sketching out the cognitive mechanisms of languaging 'conceptual complexes' or mental categories through grammar means, the authors endeavour to define and formulate their semantic representations which are supposed to meet three prime objectives, namely to 1) reflect the orientation effect of grammar forms and constructions used in the process of speech production as coordination of his/her own interactions; 2) interpret the meaningful content and mental imaging associated in the subject's mind with this or that grammar form; 3) serve as an auxiliary technique in understanding and explaining English grammar for various teaching and learning purposes. The proposed approach and delineated technique are showcased by the verbs forms of present simple and present progressive whose cognitive essence and interpretative models are described and analysed in minute detail.
\end{abstract}

Keywords: Cognitive grammar; cognition, English tense forms, simple and progressive tenses.

\footnotetext{
*ADDRESS FOR CORRESPONDENCE: Andrey Druzhinin, Department of Foreign Languages, Moscow State Institute of International Relations - Ministry of Foreign Affairs, 119454, Russia

E-mail address: andrey.druzhinin.89@mail.ru
} 
Druzhinin, A., Pesina, S. \& Rahimi, A. (2017). Bio-Cognitive aspects of simple and progressive verb forms usage. Global Journal of Foreign Language Teaching. $7(1), 46-51$.

\section{Introduction}

What is grammar? The question posed sounds understandably tricky but only after we have figured out the answer, we will we be able to carry on with our research into the particulars of English verb constructions with a view to work out a better understanding of their use, meaning and functioning.

What seems to be of utmost importance here is that we leave behind the 'old good' formula dictating that grammar is a set of rules under which syntactic structures are built up. The matter is that if a language is ontologically a physiological ability of a human (which can hardly be denied by anybody), we must unavoidably speak of that very human first. More than that, there is no escaping the fact that it should become the focus of our attention because speech production, generation of sense and communication depend and cannot but depend on the producer, generator and communicator. It means that any attempt to unearth the linguistic truth from the researched subject-matter invariably involves an anthropocentric approach according to which we take a subject-oriented view and look at things from the perspective of a 'language speaker' (Cowley, 2004; Arhipov, 2008; Pesina \& Solonchak, 2015).

This 'language speaker' is a subject who perceives the surrounding reality through sensory organs, which makes it possible to receive the necessary information from the outer world with an aim to biologically 'survive', i.e. a d a p t to it more effectively. This subject of perception by virtue of the innate higher nervous activity possesses cog $\mathrm{nition}$ allowing this person both to perceive and conceive the reality as well as making possible the development of such a specific capacity as I a n g u a g e. This capacity in turn is meant to greatly facilitate the process of adaptation and conception by opening up an opportunity to describe, represent or 'translate' the formed mind images and concepts from the person's concept map of the world. Being also a member of a (social and cultural) language community, the subject accordingly shapes their own language map of the world specific to this community. The latter is nothing short of a person's language competence as a body of knowledge they have to be sure they can make themselves clear and describe the right mental image of what they have perceived and conceived to be adequately understood.

How does this shaping of 'maps' take place and how do we grammatically put to language what we think? Since the very birth, a human as a cognitive being begins to interact with his or her environment reacting to the outer stimuli and making observations so that a certain pattern of behavior is settled to guarantee the safe survival. These interactions or their eventualities being valuable and vitally meaningful to the subject (e.g. hot water is painful) are remembered in the form of images and accumulate the subject's experience. It means that he or she can freely make use of this experience for reaching a positive result in every successive interaction which is more complex and intricate than the previous ones. Such a growing network of experienced interactions coupled with the piling knowledge of them and their meaning are essential to the human's efficient adaptation to the environment.

The same goes for language. Since birth, a human as a social being is immersed in the environment of language interaction. An elementary word uttered to a child with reference to an object or fragment of reality becomes a stimulus to react to and observe. The next utterance of this word in the same situation of reference causes the subject to remember this interaction and 'come to terms with' it (like hot water) and imbibe it as part of experience. In this way, a word becomes meaningful, i.e. a child is able to associate the content (what was referred to in those preceding situations of utterance) with the form (the graphic and sound image of the word), understand and make use of this meaning in the future.

As a person's brain becomes mature, it makes it possible for them to recognize more complicated notions and concepts as well as concurrently operate on the acquired units of linguistic experience to describe these 'conceptual complexes' (categories). The latter may be called so because they represent mental products of abstraction, the mechanism of a higher level of thinking when a subject comes to grasp not only the ideas of concrete objects around, but also the notions of intangible relations in time and space. Such a wide spectrum of relations cannot be expressed by a set of words 
only (our memory will probably fail to get hold of so many images of separate words to semantically accommodate the fluidity of ever-changing environment), they need to be specially organized and combined with each other. From this moment on a person learns to operate on words and forms by recognizing the same dynamic relations within the language environment (Cf.: incoherent go - I - there - yesterday and coherent I went there yesterday). Hence, the individual establishes language routines, i.e. a settled practice of using certain words in fixed combinations to represent mental categories. More, Importantly, words and forms in these combinations do not change or transform their meanings (becoming main or un-main verbs), they remain to be associated with what was once memorized as a meaningful content or image of their language form. In other words, an organized combination of forms (grammar construction) used in discourse triggers a respective combination of images which begins to be mentally organized as well and understood as something more complex and structured (cognitive structure).

The given approach to grammar and its acquisition is felt to offer such a perspective of its phenomena and formal units that may facilitate our understanding and can help us explain it in terms of many academic and non-academic purposes. Verb forms undoubtedly come first on the list of the trickiest items of English grammar.

\subsection{Simple and Progressive: Background}

Hardly will any English learner deny the fact that once they encountered the terms 'progressive' and 'continuous', they began to picture in their minds all of those long, continuous, processual actions which later have been identified with the 'be doing' form. Unfortunately, the rosy pictures painted by repetitive grammar rules appear to be in danger of falling apart when students face the following examples:

He waited for her for a long time yesterday.

She laughed until she was blue in the face.

You talk like a child now.

Every teacher who has ever dealt with such a situation must know what it takes to explain to their students at least somehow the rationale behind the choice of verbs in the sentences. We must admit it cannot be absolutely transparent for teachers themselves either, especially when hardly is any grammar book ready to offer an informative clarification in this respect.

What we suggest in the very first place is that we stop focusing on the conventional appellations to prevent learners from delusions and potential wrong reasoning. Let them be 'the so-called simple/progressive' forms. Then, by way of introduction into these aspect-tense forms, we recommend appealing to mental pictures and images. If we try to describe what associations are triggered in our mind when we hear the contrasted words dance vs. dancing irrespective of their time reference, we will probably say that there is one image out of the two that is easier to conjure up and is seen more vividly. Beyond any doubt, it will be the image of dancing. The ING-form of the verb seems to suggest a higher degree of our involvement in the action, it is as if are eyewitnessing, observing the dance, we are part of it. On the contrary, the picture of the verb dance appears to be rather obscure and requires some effort to paint in our imagination. Strictly speaking, it would probably be a kind of sketch rather than a picture.

It might come as surprise, but this mental operation provides a good insight into the minds of English speakers themselves when they are using simple and progressive forms. These two verb forms help them describe the present/past/future as they perceive it with the reference to different forms of perception. As a matter of fact, in describing reality we can draw on two kinds of our experience, sensual (visual, aural) and socially gained (knowledge-based). In other words, we can see (less commonly hear, feel) something happening before our eyes or know that something happens because we have gained knowledge from the society, i.e. from books, from what somebody said, from what has been taught and educated. Therefore, simple forms epistemically orient us toward something that is commonly known or understood, i.e. common knowledge, while progressive forms orient us toward something that is immediately and individually observed, i.e. a person's visual perception. 


\subsection{Present Simple vs. Present Progressive}

We will spell out this meaningful difference with the help of cognition-based semantic interpretations that follow the examples from discourse.

The train leaves at $5 .=$

It is known that: the train [should] leave at 5.

The timetable under which the train is due to arrive and leave is publicly known, that is why the speaker refers to common knowledge. Interestingly, the use of the present tense in this example can be easily explained by the subject's perceiving the action as part of the presently existing, valid schedule. It should be noted that to facilitate the understanding of present simple forms in the situations under analysis we suggest resorting in our interpretation to the semantic extension 'should' which helps express the idea of expectation based on certain background knowledge.

The car is driving by. =

I can see: the car [in the middle of] driving by.

We would presume that the sense of immediate observation can be effectively and most fully conveyed by the interpretation hedge ' $\mathrm{l} / \mathrm{you} / \mathrm{he}$ can see' depending on the identified figure of observer with an added semantic insertion 'in the middle of' indicating immediacy as such. As a matter of fact, when we observe something as if standing by the window and looking through it, we see the action in the middle of its happening (as if in the meantime, i.e. in the middle of time).

In these examples, we observe the cases of present simple usage typifying the situation of understanding rather than knowing:

Why don't you drink your coffee now? =

It is understood that: you [should] drink your coffee now.

Where do we go now? =

It is understood that: we [should] go, where?

In the situations of speech cited above the subject describes the actions on the basis of logical reasoning and understanding which in turn result from socially acquired knowledge. Even if the actions (particularly in the first example) can be notoriously branded as 'presently progressive' from the angle of pure semantics, cognitive background to the discourse fragment in question indicates that the subject of speech does not draw the listener's attention to something that can be visually observed only.

Another set of tricky examples seems to reflect the same idea and serve as a good opportunity to work out the delusions of traditional grammar presentation:

You behave like a child! =

It is understood that: you [should not] behave like a child!

(Your childish behavior is analytically inferred by me from the situation, I understood this by drawing parallels and comparisons in my mind).

? You are behaving like a child! =

I can see: you [in the middle of] behaving like a child!

(The idea of signaling the observer's individual visual perception seems disorienting, thus the sentence sounds weird).

I give up. You win. =

It is understood that: I [should] give up. You [should] win.

? I'm giving up. You're winning. =

You can see: me [in the middle of] giving up. I can see: you [in the middle of] winning.

The following contrasted pair of sentences featuring the use of always with both verb forms exemplifies the underlying principle of common vs. individual differentiation:

Dogs always bark at cats. =

It is known that: dogs [should] always bark at cats.

This dog is always barking at me. =

I can see: this dog always [in the middle of] barking at me.

As is clear from the discourse fragments, the speaker refers to different sources of information about 
the described event. In the first situation, it is their knowledge of something commonly expected, while in the second case the speaker indicates their own individual visually-based experience with the dog (every time the speaker sees this dog, it is barking). It is worth mentioning that despite the age-old tradition to associate the use of always and the progressive form with annoyance, one can easily encounter a number of phrases of this kind:

I'm always looking for something new (lyrics). =

I see myself: always [in the middle of] looking for something new.

My mother is always bringing home some extra work (CFCE). =

I see my mother: always [in the middle of] bringing home extra work.

Meanwhile, in this sentence the choice of verb forms may strike one as unexpected, but only at a glance. After undertaking some cognitive interpretation effort, we can reveal the speaker's true vision of the situation described and intentions in mind:

My mum always comments on what I'm wearing (OALD). =

It is known that: my mother [should] always comment + on what she sees: me wearing.

The speaker's mother is known and always expected to give a comment on the speaker's clothes because it might be an established tradition running in the family or characteristic attributed to her by the people who know her. One way or another, it is implied that it does not happen purely in view of the speaker. The second part of the sentence presupposes the observer's (the mother's) visual perception even if 'by law' the action may well be treated as regular or habitual.

In the fluid environment and amidst the dynamics of the reality around, our cognition seeks ways to better adjust to or, figuratively speaking, 'digest' the information charge it continually receives. For example, it tends to identify unrelated objects or phenomena as being the same or similar on the basis of a certain shared property. This relationship finds its manifestation in language - both objects or phenomena are described or referred to by one and the same language form. Such concept transfers (generally known as metaphor) are absolutely essential to natural communication; otherwise, we would be at a critical loss for separate words to describe every single fragment of reality. If we look at grammar and the verb forms under discussion, we will spot this metaphor in the following cases:

He is arriving tonight.

We are giving a party tomorrow.

Both these actions are semantically directed at the future, yet the speaker chooses the present progressive form to describe them. Apparently, the speaker perceives them as happening as if (or literally?) before their eyes for the reason that these actions are indirectly observed:

He is arriving tonight. =

You can see: him [in the middle of] arriving tonight.

(I am preparing for his arrival, I am waiting for the train, I am not planning any other important events for tonight).

We are giving a party tomorrow. =

You can see us: [in the middle of] giving a party tomorrow.

(We are arranging the dates, choosing the music, inviting the guests, etc.).

Similarly, the idea of indirect visual perception can be traced in such colloquial present progressive usage as given below:

Oh no! I am not staying at this hotel one more time. =

You can't see: me [in the middle of] staying at this hotel.

(Look at me! You see, don't you? How can I stay there again?).

You are not sleeping in my bed! Get out! =

I can't see: you [in the middle of] sleeping in my bed!

(Look at me! I don't see you sleeping here! Get out!).

In these situations, the speaker centers the listener's attention on their individual perception of the action as they see it (though not literally before their eyes) to make the adequate orienting impression, namely that of refusal or strict order.

\section{Conclusion}


It is known that the effect of cross-disciplinary perspective on linguistics consists in enhancing explanatory power. It stands to reason that this statement is fundamentally sound in the context of the undertaken research into English grammar. Its chief aim is not so much to provide an alternative description of the ongoing linguistic issues or explore the age-old subject matter as to prove the practical value and applicability of what we would rather call a shift of perspective. It remains for the readers themselves to decide how radical this shift may look and sound and if they are ready to adopt it theoretically. The 'new look' offered here focuses on what might be introduced into practice, be it a classroom grammar drill, independent learning or other language problem-solving emergencies. It could hopefully expand the horizons of hands-on approaches to grammar English teachers are so eagerly looking to nowadays, no matter how deep-rooted is the structure-oriented view of grammar is around and how much or little they want to change it. The point is that everyone can at least catch a glimpse of the presented interpretations and in prospect choose which they feel to be more explanatory, functional or better fitting to help them cope with similar usage situations of English tense forms.

\section{References}

Arhipov, I. K. (2008). Jazyk i jazykovaja lichnost' [Tekst] / I. K. Arhipov. - SPb: OOO «Knizhnyj dom». - 248 s.

Cowley, S. J. (2004). Contextualizing bodies: human infants and distributed cognition. Language Sciences, 26(6), 565-591.

Oxford Advanced Learner's Dictionary, $8^{\text {th }}$ ed. - Oxford: Oxford University Press, 2010.

Pesina, S., \& Solonchak, T. (2015). Concept in Cognitive Linguistics and Biocognitive Science // Procedia - Social and Behavioral Sciences, 192(24), 587 - 592.

Pesina, S., \& Solonchak, T. (2015). Word Functioning in Communication Process // Procedia - Social and Behavioral Sciences, 192(24), $346-351$. 